\title{
Uterine artery embolisation in the management of recurrent vaginal haematoma
}

\author{
N S Chauhan, ${ }^{1}$ MS; S B Dhodhapkar, ${ }^{1}$ MD; M Daniel, ${ }^{1}$ MD, DGO; M C Arokiaraj, ${ }^{2}$ MD, DM; R C Chauhan, ${ }^{3}$ MD \\ ${ }^{1}$ Department of Obstetrics and Gynecology, Pondicherry Institute of Medical Sciences, Puducherry, India \\ ${ }^{2}$ Department of Cardiology, Pondicherry Institute of Medical Sciences, Puducherry, India \\ ${ }^{3}$ Department of Community Medicine, Pondicherry Institute of Medical Sciences, Puducherry, India
}

Corresponding author: N Singh Chauhan (drneelimasingh30@gmail.com)

We report a rare case of primary postpartum haemorrhage due to a traumatic cause following spontaneous vaginal delivery in which surgical intervention failed. It was successfully treated by transcatheter embolisation of the uterine artery. This technique, although well known, is still underused in such conditions.

S Afr J Obstet Gynaecol 2015;21(2):46-47. DOI:10.7196.SAJOG.906

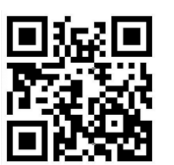

Postpartum haemorrhage (PPH) is commonly defined as blood loss of $500 \mathrm{~mL}$ or more within 24 hours of birth; severe $\mathrm{PPH}$ is blood loss of $1000 \mathrm{~mL}$ or more within the same time. PPH affects approximately $2 \%$ of all women following delivery, resulting in nearly one-quarter of all maternal deaths globally, and it is the leading cause of maternal mortality in most low-income countries. PPH is a significant contributor to severe maternal morbidity and long-term disability. ${ }^{[1-3]}$

Uterine atony is the most common cause of $\mathrm{PPH}(70 \%)$, but genital tract trauma (i.e. vaginal or cervical lacerations), uterine rupture, retained placental tissue or maternal coagulation disorders may also result in $\mathrm{PPH}^{[4]}$ Coagulation disorders especially contribute to maternal morbidity rather than mortality.

When medical measures fail to control postpartum bleeding, bilateral uterine or hypogastric artery ligation may be attempted. However, owing to extensive collateral circulation in the pelvis, the success rate of bilateral hypogastric artery ligation ranges from $40 \%$ to $100 \%{ }^{[5]}$ and uterine artery ligation has been shown to have a success rate of $92 \% .{ }^{[6]}$ Both these techniques aim to leave the uterus intact and preserve fertility. In 1979, transcatheter embolisation to control postpartum bleeding was initially described by Brown et $a l .{ }^{[7]}$ Since then, several authors have reported the usefulness of this technique as first-line treatment for atonic PPH in patients who are refractory to conservative treatment, ${ }^{[8,9]}$ but its use in puerperal haematomas in which surgical intervention fails to control bleeding is still under-reported. We present this case report to highlight the use of transcatheter uterine artery embolisation in cases of postpartum haemorrhage due to vaginal haematoma that did not respond to surgical intervention.

\section{Case report}

A 28-year-old woman, G2P1L1, was admitted in active labour at 39 weeks' gestation. Four hours later, she delivered a live baby weighing $3250 \mathrm{~g}$ by spontaneous vaginal delivery with seconddegree laceration. Oxytocin $10 \mathrm{U}$ intramuscularly was given as a bolus followed by an infusion of $10 \mathrm{U}$ in $500 \mathrm{~mL} 0.9 \%$ saline over 4 hours. The delivery was uneventful and blood loss was estimated at $300 \mathrm{~mL}$.
The patient was initially stable with a blood pressure of $120 / 80 \mathrm{mmHg}$, pulse rate of $90 \mathrm{bpm}$ and respiratory rate of 18/ min. Two hours later she complained of excessive vaginal pain. Examination showed a blood pressure of $110 / 70 \mathrm{mmHg}$, a pulse rate of $100 \mathrm{bpm}$ and a respiratory rate of $22 / \mathrm{min}$. The uterus was well retracted, but vaginal examination revealed an $8 \times 6 \mathrm{~cm}$ haematoma in the left lateral vaginal wall that was separate from the stitch line. The patient was moved to theatre and intravenous sedation was given. The haematoma was explored, perineal stitches were removed and about $500 \mathrm{~mL}$ of blood clots were removed. The vagina was closed with deep continuous interlocking sutures. After complete haemostasis was achieved, the cervix and vagina were explored and found to be normal. The patient was catheterised and adminstration of oxytocin $40 \mathrm{U}$ in $500 \mathrm{~mL} 0.9 \%$ saline was started, along with other uterotonics. After assessment of the patient's condition, two units of blood were transfused and she was monitored hourly.

However, 6 hours later, the patient again experienced the same symptoms with accompanying hypotension. On examination, she was found to be pale with a blood pressure of $100 / 60 \mathrm{mmHg}$, a pulse rate of $108 \mathrm{bpm}$ and a respiratory rate of $24 / \mathrm{min}$. Abdominal examination showed the uterus to be well retracted, but there was a left ischiorectal fossa swelling. Vaginal examination again revealed a $12 \times 12 \mathrm{~cm}$ haematoma in the left lateral vaginal wall, which was about $3 \mathrm{~cm}$ short of the left fornix. The anterior and other vaginal walls were free. On rectal examination, the mass was palpable in the rectovaginal space with the rectal mucosa free. After informed consent, the patient was transferred to the operating theatre for exploration and evacuation under general anaesthesia. During exploration about $1000 \mathrm{~mL}$ of blood clots were removed and resuturing was done. All bleeding points were identified and ligated. Dead space was obliterated with deep figure-of-eight sutures. Vaginal packing was done after complete haemostasis was secured. During surgery, the patient was transfused two units of blood and three units of fresh-frozen plasma (FFP) while the oxytocin infusion was continued. At the end of the operation, the patient was haemodynamically stable. In the recovery room after 1 hour her blood pressure dropped to $80 / 40 \mathrm{mmHg}$. Her heart rate was $110 \mathrm{bpm}$ and oxygen saturation 99\%. Examination revealed active bleeding from the vagina with a well-retracted uterus. A series of 
haematological investigations were done, showing a haemoglobin concentration of $7.2 \mathrm{~g} / \mathrm{dL}$ and a platelet count of $78 \times 109 / \mathrm{L}$. Coagulation studies showed an international normalised ratio of 1.2 and activated partial thromboplastin time (APTT) of 30.1 seconds (normal 26.2 seconds). After much discussion, embolisation of the uterine artery was planned.

The patient was transferred to the cardiac catheterisation laboratory. An injection of $10 \mathrm{~mL}$ xylocaine $(2 \%)$ was infiltrated and the left femoral artery was cannulated with a $6 \mathrm{~F}$ sheath. Angiogram using ioxol contrast showed active bleeding from the left uterine artery, and no other bleeding point (Fig. 1). Embolisation was performed successfully with $500 \mu \mathrm{m}$ polyvinyl alcohol (PVA) as shown in Fig. 2. A repeat angiogram showed no further bleeding (Fig. 3). The patient was transferred back to the intensive care unit and further blood products were transfused as required according to laboratory results.

Thirty-six hours after haematoma formation, the haematological parameters returned to acceptable limits (haemoglobin $9.6 \mathrm{~g} / \mathrm{dL}$, platelets $92 \times 109 / \mathrm{L}$, INR 1.2, APTT 33 seconds). Chest X-ray showed no sign of acute lung injury. A total of six units of packed red cells and five units of FFP were transfused. The patient's condition improved and she was discharged from hospital 8 days after her operation. At follow-up 4 weeks later, she remained well with no further complaints.

\section{Discussion}

Approximately $30 \%$ (in some countries over $50 \%$ ) of direct maternal deaths worldwide are due to haemorrhage, mostly in the postpartum period. ${ }^{[1]}$ In India, PPH is currently the most common direct cause of maternal death.

During pregnancy the uterus, vagina, and vulva have rich vascular supplies that are at risk of trauma during the birth process; trauma to these highly vascular areas may result in formation of a haematoma. Puerperal haematomas occur in 1:300 - 1:1 500 deliveries and, rarely, are a life-threatening complication of childbirth. ${ }^{[10,11]}$ Vaginal/paravaginal haematomas result from injuries to branches of the uterine artery, mainly the descending branch. ${ }^{[12]}$ These haematomas are usually

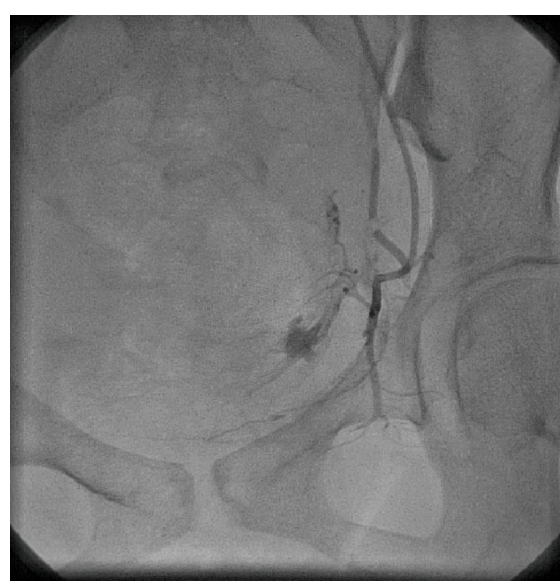

Fig. 1. Active bleeding from left uterine artery.

associated with forceps delivery, but may also occur following a spontaneous delivery. In contrast to the vulva, vessels in the vagina are surrounded by soft tissue and do not lie in the superficial fascia. Trauma to these vessels can therefore lead to a large accumulation of blood in the paravaginal space or ischiorectal fossa, resulting in considerable delay in diagnosis.

Transcatheter arterial embolisation has been reported as a method of haemorrhage control since the 1960s, and is widely used in the control of pelvic haemorrhage due to malignancy, trauma and radiation. This technique has recently been used successfully in the control of $\mathrm{PPH} \cdot{ }^{[13]}$ Advantages of this procedure are easy identification of the bleeding site, preservation of the uterus and fertility, while rebleeding from collateral vessels is rare. Complications occur in only $8.7 \%$ of cases, the most common being lowgrade fever, and rarer ones including pelvic infection and groin haematoma. ${ }^{[13]}$

\section{Conclusion}

Our case shows that selective arterial embolisation of the uterine arteries is an effective method of treating puerperal haematoma refractory to conventional firstline therapy, and an effective alternative way of achieving haemostasis with minimal morbidity.

1. Khan KS, Wojdyla D, Say L, Gülmezoglu AM, van Look PF WHO analysis of causes of maternal death: A systematic review. Lancet 2006;367(9516):1066-1074. [http://dx.doi. org/10.1016/S0140-6736(06)68397-9]

2. Campbell OM, Graham WJ, Lancet Maternal Survival Series Steering Group. Strategies for reducing maternal mortality:

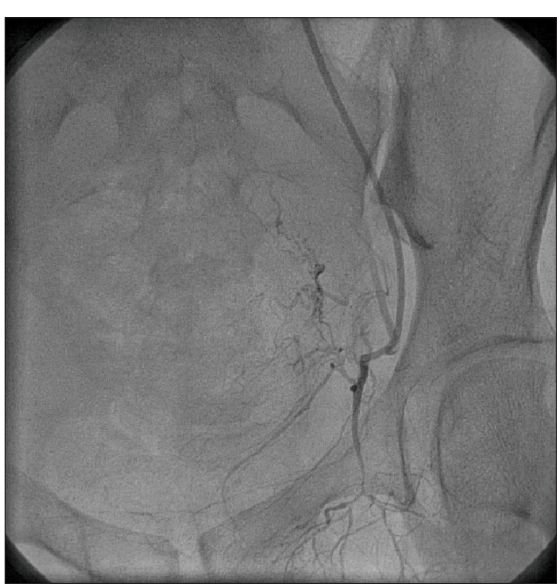

Fig. 2. Embolisation being performed.

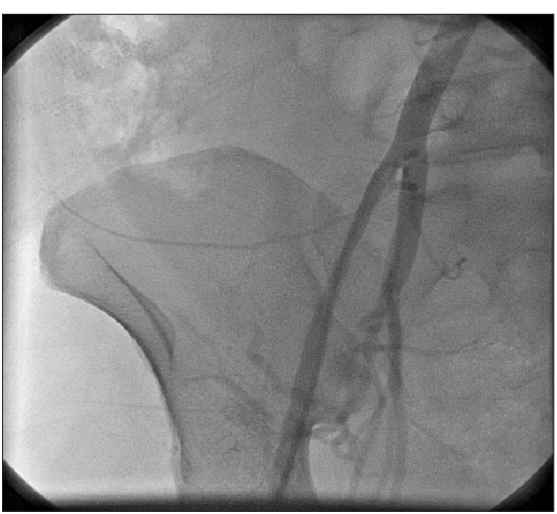

Fig. 3. Angiogram showing no further bleeding.

Getting on with what works. Lancet 2006;368(9543):1284 1299. [http://dx.doi.org/10.1016/S0140-6736(06)69381-1]

3. Souza JP, Gülmezoglu AM, Carroli G, et al. The World Health Organization Multicountry Survey on maternal and newborn health: Study protocol. BMC Health Services Research 2011;11:286. [http://dx.doi.org/10.1186/1472-6963-11-286]

4. World Health Organization, Department of Reproductive Health and Research. Managing Complications in Pregnancy Health and Research. Managing Complications in Pregnancy
and Childbirth: A Guide for Midwives and Doctors. Geneva: and Childbirth: A Guide for Midwives and Doctors. Geneva:
WHO, 2000. http://www.who.int/reproductivehealth/publications/maternal_perinatal_health/9241545879/en/index. $\mathrm{html}$ (accessed 26 June 2014).

5. Evans S, McShane P. The efficacy of internal iliac artery ligation in obstetric hemorrhage. Surg Gynecol Obstet 1985;160(3):250-253.

6. Abd Rabbo SA. Stepwise uterine devascularisation: A novel approach technique for management of uncontrollable postpartum haemorrhage with preservation of the uterus. Am J Obstet Gynecol 1994;171(3):694-700.

7. Brown BJ, Heaston DK, Poulson AM, et al. Uncontrollable postpartum bleeding: A new approach to hemostasis through angiographic embolization. Obstet Gynecol 1979;54(3):361365 .

8. Gonsalves M, Belli A. The role of interventional radiology in obstetric hemorrhage. Cardiovasc Intervent Radiol 2010;33(5):887 895. [http://dx.doi.org/10.1007/s00270-010-9864-4]

9. Lee JS, Shepherd SM. Endovascular treatment of postpartum hemorrhage. Clin Obstet Gynecol 2010;53(1):209-218 [http://dx.doi.org/10.1097/GRF.0b013e3181ce09f5]

10. Zahn CM, Yeomans ER. Postpartum hemorrhage: Placenta accreta, uterine inversion, and puerperal hematomas. Clin Obstet Gynecol 1990;33(3):422-431.

11. Villella J, Garry D, Levine G, et al. Postpartum angiographic embolization for vulvovaginal hematoma: A report of two cases. J Reprod Med 2001;46(1):65-67.

12. Ridgway LE. Puerperal emergency. Vaginal and vulvar hematomas. Obstet Gynecol Clin North Am 1995;22(2):275-282.

13. Vedantham S, Goddwin SC, McLucas B, Mohr G. Uterine artery embolization: An underused method of controlling pelvic hemorrhage. Am J Obstet Gynecol 1997;176(4):938948. [http://dx.doi.org/10.1016/S0002-9378(97)70624-0] 